\title{
A capitalização como falsa solução para a saída da crise
}

Pierre Salama

\section{Introdução}

A América Latina e hoje, mais particularmente, o Brasil e a Argentina conhecem ou uma desaceleração de seu crescimento ou uma profunda crise. A crise pela qual passa a Argentina é muito importante pela sua amplitude e pelos efeitos sociais, mas também porque ela desnuda as falhas da política de liberalização do governo do presidente Macri. A crise pela qual o Brasil passa (2015-2016) é a mais importante, desde os anos 1930: as desigualdades e a pobreza aumentaram consideravelmente, apagando qualquer melhora obtida durante os dois mandatos de Lula e o primeiro mandato de Dilma.

O novo governo brasileiro herda uma situação econômica contrastante: com bons fundamentos, mas uma situação econômica deteriorada e uma inserção internacional problemática com uma incapacidade de retomar o desenvolvimento anterior à crise de 2015-2016. Ao término do ano de 2018, certos fundamentos são positivos: um fraco déficit da balança de contas correntes de -0,7 do PIB; um saldo primário do orçamento (excetuando-se o serviço da dívida pública) de -2,3\% do PIB, em baixa desde a crise, mascarando, no entanto, um déficit nominal ainda muito elevado de $-7,3 \%$ do PIB, por causa do peso do serviço da dívida pública; uma taxa de inflação moderada (3,75\% para o IPCA, Índice de preços ao consumidor); das reservas internacionais elevadas (375 milhões de dólares) que são explicadas essencialmente pelas entradas de capitais, sobretudo os investimentos estrangeiros direitos (79

\section{$\overline{\text { Pierre Salama }}$}

Professor emérito da Universidade de Paris XIII, CEPN-CNRS UMR 7234, e latino-americanista. E-mail: pierresalama@gmail.com 
milhões em 2018). Os aspectos negativos são principalmente um crescimento pífio de 1,1\% em 2018 (depois de 1,15 em 2017), enquanto poderíamos esperar uma forte recuperação, após a crise de 2015 - 2016, de -3,6 e -3,5\% respectivamente de queda do PIB, uma taxa de desemprego de dois dígitos, um crescimento precário com forte tendência ao declínio, uma dívida pública considerável e uma incapacidade crescente de se inserir positivamente no mercado internacional. O ano de 2019 deveria ser dedicado a um forte crescimento, mas, a cada dia que passa, esta esperança se mostra vã e o crescimento será muito menor que o esperado.

A corrente liberal considera que o excesso de impostos e contribuições necessariamente produz um efeito de evicção sobre a poupança destinada ao investimento. Em outras palavras, o pagamento de impostos impede que aqueles que desejam investir possam fazê-lo. A diminuição da carga tributária deve, portanto, incentivar o investimento. Essa relação é mais um mito do que uma análise séria. As despesas públicas, financiadas por receitas e contribuições fiscais, que promovem economias externas, têm efeitos multiplicadores e podem produzir maior lucratividade da qual o setor privado se beneficiaria, assegurando um mínimo de solidariedade intergeracional ao sistema de distribuição para reduzir a pobreza e a desigualdade de renda. Inversamente, a poupança aumentada pela redução da carga tributária não necessariamente se move em direção ao investimento produtivo e pode ser destinada à compra de bens de consumo bem como, especialmente, a investimentos financeiros.

No entanto, esta é a proposta do governo Bolsonaro. Entre outras medidas, passar de um sistema de distribuição para um sistema de capitalização seria uma solução para sair da crise e recuperar a confiança dos mercados e o alto crescimento.

O objetivo deste artigo é analisar as razões pelas quais o sistema previdenciário latino-americano deve evoluir à luz da transição demográfica, sem entrar em um sistema de capitalização quando existem sistemas de distribuição. 


\section{Do passado-presente...}

Estes últimos quarenta anos caracterizam-se por uma tendência à estagnação do PIB per capita e pela desindustrialização na maioria dos países latino-americanos (CASTILHO; MARTINS NETO, 2016; SALAMA, 2014; RODRIK, 2016; MONCAVO JIMENEZ, 2013). Ao contrário de uma ideia relativamente compartilhada, essas economias têm sido pouco ou não emergentes, com exceção da primeira década dos anos 2000. Elas não convergiram ou convergiram muito pouco para o nível de renda per capita dos países avançados, ao contrário do que se passou em inúmeros países asiáticos. O Brasil, país emblemático por seu peso econômico, pela influência política liderada pelo presidente Lula (2003-2011), pelo resultado das últimas eleições presidenciais que levaram a extrema direita ao poder em 2019, não conhecem esta convergência. Seu PIB per capita, medido pelo padrão dos Estados Unidos, não converge. É aproximadamente o mesmo que na primeira década de 1960, emboraele tenha se aproximado. A Coréia do Sul, desdeo início dos anos 1990, mostra um desempenho mais elevado que o Brasil, revelando que a tendência à estagnação não é inevitável.

\section{Figura 1: Renda per capita do Brasil e da Coréia do Sul, 1960-2016} De 1960-2016.

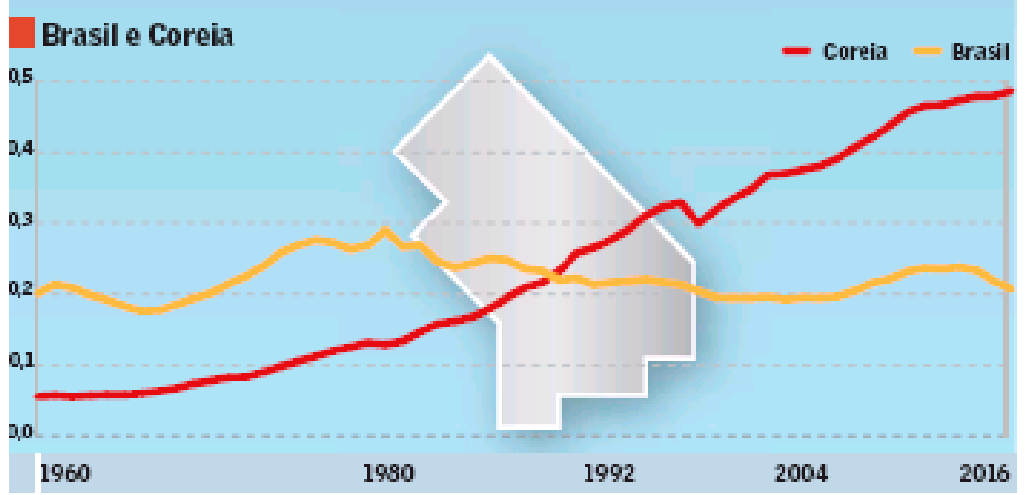

Fonte: O Valor, 13 dez. 2018.

A melhoria do nível de vida das classes média-baixa e média, alimentadas no começo dos anos 2000 por um certo otimismo 
sobre a perspectiva de vida, os conduziu a ser mais "tolerantes" (HIRSCHMAN; ROTHSCHILD, 1973). No entanto, este não era mais o caso desde 2014 no Brasil e em inúmeros outros países. A tolerância transformou-se em intolerância com a acentuação da reprimarização da economia, a continuação da desindustrialização e da crise de 2015-2016.

Com a reprimarização da economia e, por consequência, sua desindustrialização, a demanda de trabalho qualificado por parte das empreses tornou-se relativamente mais rara, abaixo da oferta de jovens recém-saídos das escolas e das universidades. Em outros termos, a reprimarização favoreceu a criação de empregos não qualificados, mesmo que a qualificação tenha aumentado. Um rebaixamento real é percebido com ainda mais força pelos jovens que ascenderam ao status de classe média. Os dados são eloquentes: 38\% dos empregados com ensino superior completo ocupam cargos menos qualificados do que aqueles que pretendiam, esta porcentagem eleva-se a 44\% para a faixa etária de 24 a 35 anos. Essas porcentagens eram inferiores em 2012: 33,4\% e 38,4\%, respectivamente, no Brasil (ver SALAMA, 2012; ROCHA, 2014; AMARANTE; COLACCE, 2018).

A América Latina e, mais particularmente, o Brasil não conheceram o milagre econômico. A reprimarização de suas economias provocou uma grande vulnerabilidade e acentuaram uma desindustrialização precoce. A pobreza diminuiu - trata-se de uma medida em termos absolutos, o que significa que ela teria podido desaparecer -, mas os rendimentos relativos das classes médias-baixa e médias diminuíram, levando a termo uma frustração. As categorias mais ricas enriqueceram e, quando a crise chegou, os partidos progressistas eram tão facilmente designados como bodes expiatórios que eles teriam negado o enriquecimento dos ricos e o empobrecimento relativo de uma grande parte das camadas médias. Eles estariam, tanto quanto outras classes, ao alcance da gangrena da corrupção. Sem compreender esses movimentos subterrâneos, não é possível lhes fazer face, logo que eles são colocados em cena. 


\section{3 ... ao presente-futuro}

Os dados aqui analisados são uma forte tendência, não são os únicos, mas são importantes. Trata-se de uma evolução demográfica e de seus efeitos potenciais sobre o sistema previdenciário em direção a uma maior capitalização e a uma menor distribuição, o último sistema tendendo a se tornar uma renda universal mínima para os idosos.

A transição demográfica foi particularmente rápida na América Latina. Como resultado, seus efeitos são sentidos mais rapidamente do que nos países avançados. A queda nas taxas brutas de natalidade e mortalidade deve levar a uma taxa de aumento populacional cada vez menor, a uma reversão da mesma e, portanto, a uma redução da população até 2045, pelo menos no Brasil, o país mais importante do subcontinente americano.

Figura 2: Brasil, população, taxa bruta de natalidade, taxa bruta de mortalidade ${ }^{1}$, 1950-2095

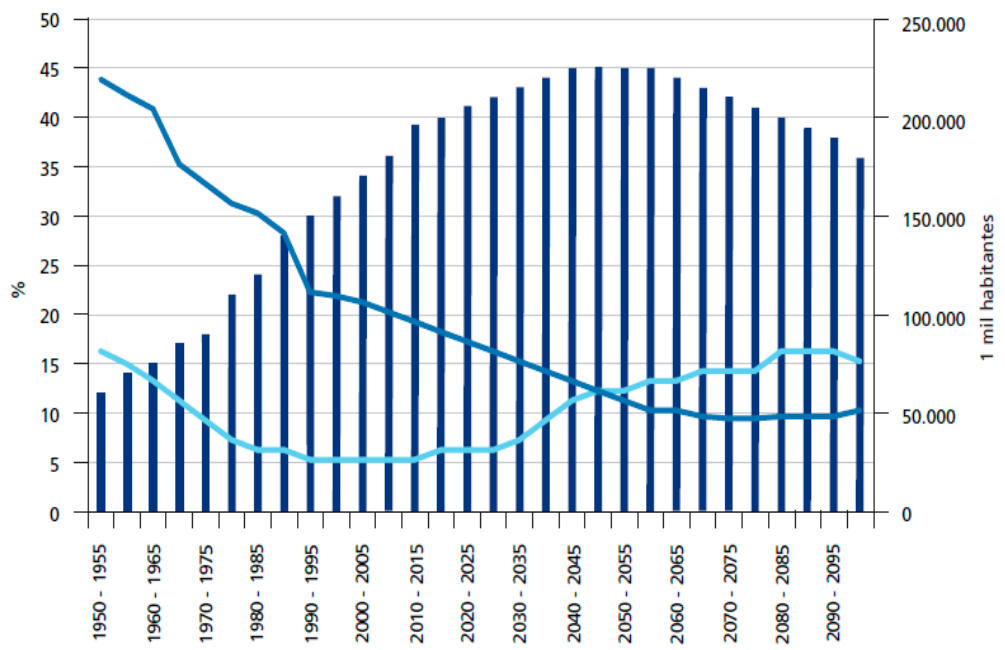

Fonte: Guellati, Monteiro e Oliveira Jr (2017).

1 Número de crianças mortas sobre a população total de nascidos em um ano. 
Coma disseminação da educação na América Latina, ${ }^{2}$ a taxa de fertilidade das mulheres diminuiu rapidamente. ${ }^{3}$ Com melhorias nos cuidados, a mortalidade infantil diminuiu e a expectativa de vida aumentou, embora menos rapidamente, para os setores mais pobres da população. Hoje, esses dados estão próximos aos observados em países avançados, como pode ser visto na tabela 2.

\section{Tabela 1: Principais indicadores demográficos de alguns países da América Latina, 2014}

\begin{tabular}{|l|l|l|l|l|l|l|}
\hline Países & $\begin{array}{l}\text { População } \\
\text { (em milhões) }\end{array}$ & 65 anos e e & $\begin{array}{l}\text { Razão de } \\
\text { de pe en } \\
\text { dencia* }\end{array}$ & $\begin{array}{l}\text { Esperança } \\
\text { de vida dos } \\
\text { homens }\end{array}$ & $\begin{array}{l}\text { Esperança } \\
\text { de vida das } \\
\text { mulheres }\end{array}$ & $\begin{array}{l}\text { PIB/t } \\
2015) \text { em \$ }\end{array}$ \\
\hline Argentina & 43 & 10.8 & 56.6 & 72.3 & 79.9 & 20.364 \\
\hline Bolivia & 10.6 & 6.3 & 64.6 & 65.5 & 70.4 & 6.954 \\
\hline Brasil & 206.1 & 7.6 & 45.1 & 70.4 & 78 & 15.391 \\
\hline Chile & 17.8 & 10.7 & 45.3 & 78.8 & 84.2 & 23.367 \\
\hline Colombia & 47.8 & 6.8 & 45.9 & 70.3 & 77.5 & 13.829 \\
\hline Equador & 15.9 & 6.5 & 55.9 & 72.9 & 78.5 & 8.620 \\
\hline México & 125.4 & 6.3 & 52.4 & 74.2 & 79 & 16.988 \\
\hline
\end{tabular}

Fonte: Figliuli(2018). *Razão entre a população com idade entre 0-14 anos e com idade superior a 65 anos sobre a faixa etária dos 15 aos 64 anos.

2 O número médio de anos de escolaridade no Brasil, em 1980, foi de 5,7 anos, e, em 2015, de 8,2 anos. No Chile, em 2015, esse dado atinge os 9,7 anos e, na Argentina, 9,2 anos. A porcentagem de crianças de 15 a 18 anos que concluíram o ensino fundamental no Brasil subiu, entre 1980 e 2010, de 48\% para 69,4\%. Ver Guellati, Monteiro e Oliveira Jr (2017).

3 De acordo com as Nações Unidas, o número médio de filhos por mulher na América Latina passou de 6, entre 1960-1965, para pouco mais de 2, entre 20002015, Esse dado deve ficar em torno de 1,8 entre 2030 - 2035 (UN, 2015). Para o Brasil, de acordo com Guellati, Monteiro e Oliveira Jr (2017), com base em dados do IBGE, a taxa de fecundidade total de mulheres em idade fértil passou de 6,3, em 1960, para 1,9, em 2010, e deve ser de 1,7 em 2020. Na América Latina, assim como no Brasil, a transição demográfica é particularmente rápida e, se a população continua a crescer em um ritmo cada vez mais fraco, é porque a geração em idade fértil corresponde a uma taxa de fertilidade maior do que o tempo "t" existente vinte anos atrás. 
Figura 3: População acima de 60 anos na América Latina e no mundo, 2015-2100

1.2015

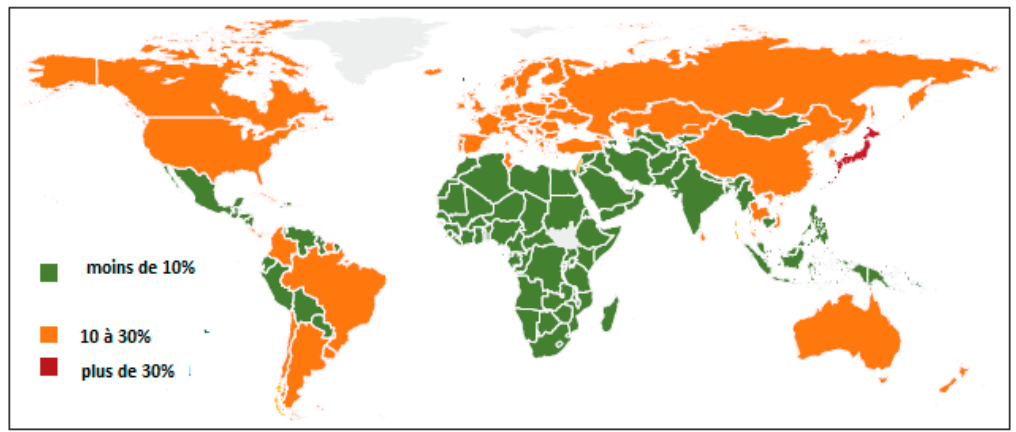

2. 2100

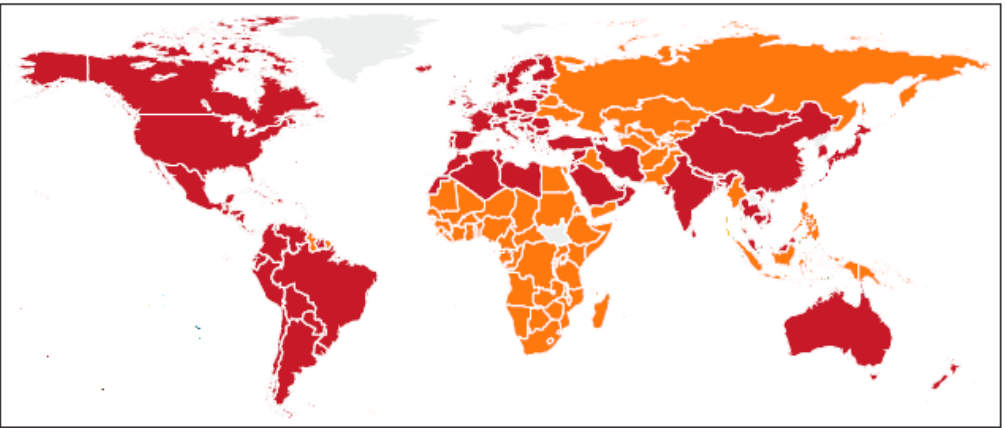

Fonte: Figliuli(2018).

Tabela 2: Gastos com saúde pública na América Latina, países selecionados, como porcentagem do PIB, 2015 -2065

\begin{tabular}{|l|l|l|l|}
\hline Países & 2015 & 2030 & 2065 \\
\hline Argentina & 6.1 & 7.4 & 12.6 \\
\hline Bolivia & 4.3 & 5.4 & 9.4 \\
\hline Brasil & 4.6 & 6.3 & 12 \\
\hline Chile & 3.8 & 5.2 & 9.5 \\
\hline Colombia & 5.5 & 7.6 & 14.3 \\
\hline Equador & 3 & 3.9 & 7.2 \\
\hline México & 3.3 & 4.4 & 8.7 \\
\hline
\end{tabular}

Fonte: Figliuli (2018). 
Dada a evolução esperada dos gastos em saúde (Tabela 2) e os principais indicadores demográficos, pode-se considerar que a razão de dependência (população menor de 15 anos mais população acima de 64 anos de idade, de 15 a 64 anos sobre a população de 15 a 64 anos), na América Latina, deve passar de 95\% em 1960 para 50\% em 2025, na América Latina e no Caribe, de acordo com dados das Nações Unidas(NU, 2015). Até 2025, haverá mais e mais inativos para menos e menos ativos. A recuperação, a partir de 2025, pode ser explicada pela desaceleração do envelhecimento da população e pelo declínio da taxa de fecundidade. As conseqüências econômicas são tanto um aumento inexorável no peso das aposentadorias e dos custos de saúde no PIB, quaisquer que sejam os sistemas, público-privado - assistencialista (sem contribuição) para a saúde, distribuição - capitalização, misto, assistencialista (sem contribuição) ou não para pensões.

No que diz respeito às aposentadorias, o sistema de distribuição favorece a solidariedade intergeracional, com os ativos pagando pelos inativos. O sistema de capitalização favorece o compromisso individual, o ativo e, às vezes, o empreendedor que o emprega, se a capitalização for obrigatória. O produto das contribuições é colocado em um fundo de pensão do mercado financeiro. Sistemas mistos existem em muitos países (distribuição concentrada no Estado, mas com uso da capitalização). Uma vez que os empregos informais são muito importantes e, como resultado, a taxa de cobertura pode ser baixa se apenas as contribuições forem levadas em conta, muitos países introduziram, em graus variados, pensões mínimas para aqueles que não poderiam contribuir por causa da baixa renda relacionada à informalidade de seus empregos.

Como pode ser visto, as taxas de cobertura são muito diferentes (Figura 4). Mais de $50 \%$ da população não recebe pensões em 2016, na Venezuela (dados de 2013), Paraguai, Colômbia (dados de 2013), República Dominicana e a maioria dos países da América Central. Além disso, a taxa de cobertura é particularmente importante na Bolívia, com uma considerável parcela não contributiva. É importante também em outros países, mais de 70\% (com exceção do Peru e do Equador), com uma grande parte não contributiva no México e no Chile. 


\section{Figura 4: Taxa de cobertura, contribuição (distribuição) e não contribuição, 2016}

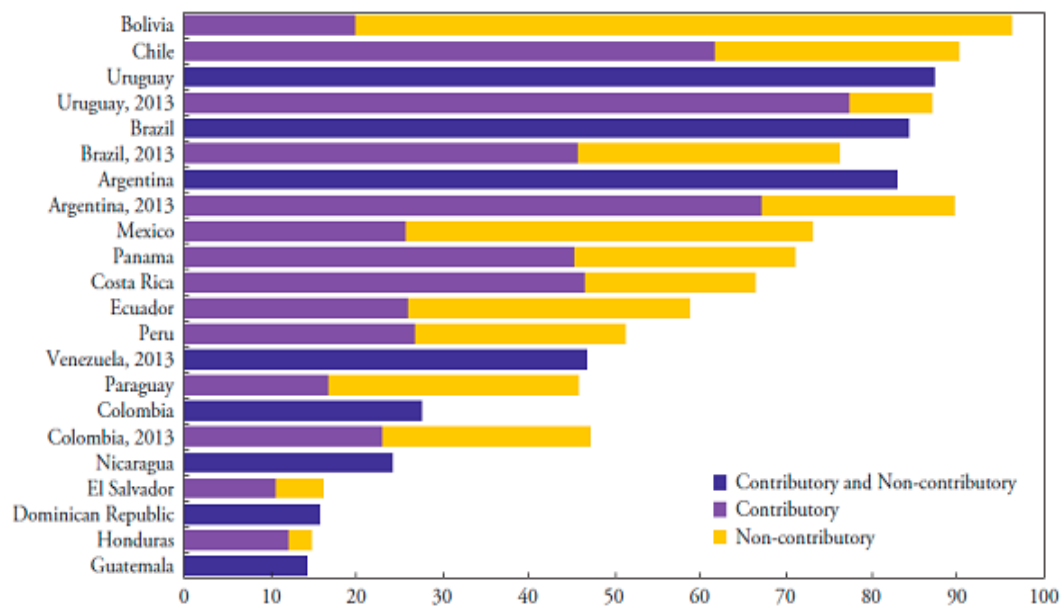

Fonte: Figliuli (2018)

Pensões pagas pelo estado (com e sem contribuições) em\% do PIB de 2015 a 2065, alguns países, 2014

\begin{tabular}{|l|l|l|l|l|}
\hline Países & Sistema de aposentadoria & 2015 & 2030 & 2065 \\
\hline Argentina & $\mathrm{R}$ & 7.8 & 8.3 & 13.8 \\
\hline Bolívia & $\mathrm{C}$ & 3 & 1.9 & 2.4 \\
\hline Brasil & $\mathrm{R}$ & 11.2 & 17.1 & 29.5 \\
\hline Chile & $\mathrm{C}$ & 4.1 & 3 & 4.8 \\
\hline Colômbia & R et C & 5.1 & 4.1 & 3 \\
\hline Equador & $\mathrm{R}$ & 2.7 & 3.5 & 6.4 \\
\hline México & $\mathrm{C}$ & 1.7 & 2.3 & 1.8 \\
\hline
\end{tabular}

Fonte: Figliuli (2018) * C: capitalização, R: redistribuição, M: misto

Estas previsões não estão isentas de problemas econômicos que exigem escolhas políticas claras. Em geral, existem duas opções. A primeira é preservar a noção de serviço público e considerar que nem tudo é comercializável, o que não exclui a avaliação de seu custo econômico e a necessidade de financiá-lo por meio de uma reforma tributária com o objetivo de fazer, principalmente, as categorias mais abastadas pagarem por uma solidariedade 
social que permitiria viver melhor em uma sociedade com benefícios sociais e, portanto,mais inclusiva. A segunda consiste em reduzir drasticamente a participação do sistema de distribuição estatal (aumentar as contribuições, prolongar sua duração, reduzir o salário de referência contra o qual a aposentadoria é calculada) em favor de um sistema de capitalização. No que se refere à saúde, a tendência é dar maior prioridade aos hospitais privados, com o desenvolvimento de sistemas de seguros privados, obrigatórios ou não. Finalmente, para a educação, a tendência é também favorecer o ensino privado nas escolas primárias e secundárias - sendo o público reservado para categorias pobres e modestas - e aumentar as taxas de inscrição em universidades públicas. O resultado é a retirada dos gastos sociais do orçamento público e um grande incremento no crédito - e financeirização que vem atrelada - para financiar parcialmente esses gastos e consequente endividamento das famílias, afetando a renda disponível sobretudo da classes mais modestas. A solidariedade ligada à redistribuição estatal diminui então acentuadamente.

Com exceção dos países que possuem movimentos sociais em larga escala, aqueles que optaram por um sistema de distribuição estão gradualmente se movendo em direção a um sistema misto que combina o sistema de distribuição - com pensões calculadas com base em um baixo salário de referência - e o sistema capitalização, obrigatória ou não, para aqueles que gostariam de ter uma pensão mais alta. Aqueles que não pudessem contribuir, porque eram pobres e/ou deficientes, receberiam uma pensão mínima perto da pensão máxima obtida através da distribuição. Isso resultaria em um sistema previdenciário universal de baixa remuneração, assim como em um sistema de capitalização cada vez maior, com muitas exceções que provavelmente seriam relativas aos militares, juízes e algumas outras categorias do serviço público. Com essas exceções, o serviço público como um todo estaria alinhado ao sistema de previdência privada (composto por elementos como: duração da contribuição, idade mínima de aposentadoria, contribuições variáveis para reduzir ou até mesmo eliminar o déficit do sistema de distribuição). Essa reforma 
aproximaria os países que optaram pela distribuição daqueles que, como o Chile, a Colômbia e o México, favoreceriam o sistema de capitalização, liberando recursos para o setor financeiro, esperando que um dia promovesse o crescimento... e não apenas especulando no mercado de ações.

\section{Conclusão}

Parafraseando Os setes loucos de R. Arlt, há sete proposições surrealistas para evitar contrariar um futuro que se anuncia difícil para a maior parte da população.

Existe uma "solução surrealista" alternativa às políticas que os governos aplicam face às crises e aos déficits produzidos pela evolução da economia mundial. Em lugar de se abrir, mesmo quando o protecionismo aumenta; em lugar de impor uma redução do poder de compra sob o pretexto de retomar a competitividade da economia, sem questionar os esforços a fazer em termos de produtividade; em lugar de perseguir uma visão rentista, que repousa sobre a exploração das matérias-primas ou em transferências massivas provenientes de trabalhadores migrantes nos Estados Unidos; em lugar de favorecer a reprimarização e favorecer os comportamentos rentistas em detrimento da industrialização, os governos latino americanos deveriam procurar uma ruptura "surrealista" com as decisões de políticas econômicas passadas.

Por isso, a inspiração no grande escritor argentino Roberto Arlt. No romance escrito no começo do século XX, Os sete loucos, Arlt faz proposições surrealistas para sair da miséria que os migrantes na Argentina desde os anos de 1920conhecem, um pouco como na França logo que os manifestantes entoaram em maio de 1968: "Sejamos realistas, peçamos o impossível".

Para sair dessa situação de crise profunda, existem sete condições surrealistas. A primeira consiste em repensar a relação do mercado interno com o mercado externo. O crescimento viria do aumento do poder de compra, isto é, do mercado interno e não do mercado externo, as economias estando relativamente fechadas. No mundo de hoje, o mercado interno e o mercado externo 
constituem um todo orgânico, favorecer um em detrimento do outro é favorecer as importações e se condenara médio prazo a desvalorizações recessivas a custos sociais elevados. A retomada do crescimento não pode existir de maneira durável sem que a competitividade aumente e sem a retomada do desenvolvimento da malha industrial. Esta é a segunda proposição "surrealista". A terceira proposição surrealista visa a romper com as políticas do meio ambiente e aquelas que limitam os direitos sociais dos cidadãos. A quarta proposição surrealista é aumentar a política de desenvolvimento com uma política industrial que favoreça as empresas "portadoras" do futuro. A quinta proposição surrealista consiste em investir massivamente na educação e na pesquisa; como fizeram os países asiáticos, procurar uma taxa de câmbio depreciada em relação ao dólar. A sexta, a mais surrealista, visa a impor uma reforma fiscal progressiva e não regressiva. Enfim, a sétima proposição surrealista é favorecer uma política de redistribuição em favor das pessoas mais vulneráveis que não seja concebida como um dever de caridade, mas como um direito delas.

Tais são as condições surrealistas, loucas para alguns, mas necessárias para aqueles que estão em harmonia com uma ética social. Como não se saberia reduzir a economia a uma "caixa de ferramentas" e a simples técnicas, estas medidas surrealistas não podem ser impostas a não ser por mobilizações sociais. A visão é estreita para evitar que se formem sombras no futuro que desencanta; contudo, esta é a única visão para frustrar esse futuro.

Estas medidas são mais eficazes e eticamente mais justas do que aquelas que consistem em aplicar uma reforma profunda no sistema de distribuição de aposentadorias, baseado na solidariedade intergeracional e em um sistema de capitalização cada vez mais financiado pelos trabalhadores e pelas empresas, reservados principalmente às classes médias e aos mais ricos. O raciocínio econômico que justifica que a única maneira de reduzir o déficit público seria reduzir o peso das aposentadorias sobre as despesas públicas e recuperar a confiança do mercado e, de maneira automática, um crescimento perdido é um raciocínio que não encontra nenhuma base sólida. O exemplo do México mostra que a taxa de crescimento médio dos últimos vinte anos é uma das mais fracas 
da América Latina, apesar de ter adotado o sistema de capitalização como o principal sistema para as aposentadorias. Além da fragilidade do raciocínio econômico que fundamenta esta proposta do sistema de aposentadoria, esta maneira de pensar assenta-se sobre o crescimento em uma confiança retomada graças à redução do déficit orçamentário e ao peso do Estado sobre o PIB. O custo social deste crescimento é elevado. As medidas surrealistas evocadas são, ao contrário, tanto para superar os problemas colocados pela demografia quanto para recuperar um crescimento mais elevado e uma mobilidade social mais importante.

Tradução do francês para o português por Érica Sales Chaves. 